\title{
Specifics of teaching engineering drawing to foreign students of construction degrees
}

\author{
Natalia Semenova ${ }^{1, *}$ \\ ${ }^{1}$ Saint Petersburg State University of Architecture and Civil Engineering, 190005, 4, $2^{\text {nd }}$ \\ Krasnoarmeyskaya st., Saint Petersburg, Russia
}

\begin{abstract}
The paper raises a number of questions helping to understand the difficulties in mastering Engineering Graphics by foreign students. It also provides answers to these questions, based on interviews and polls with foreign students studying at the Saint Petersburg State University of Architecture and Civil Engineering (SPbSUACE). A series of recommendations on organizing the educational process for foreign students studying architecture and civil engineering is provided. The paper considers issues of the availability of specialized literature, conducting additional consultations, organizing monitoring of academic performance, creating special educational groups, organizing an additional introductory course, using multimedia technologies, etc.
\end{abstract}

\section{Introduction}

The process of obtaining higher education in Russia by foreign students has some essential features. Along with difficulties experienced by ordinary students in the process of studying, there is a number of additional problems that need to be taken into account when designing an educational course.

In addition to such obvious problems as adapting to the intensity and requirements of the educational process, being placed into a group of unfamiliar people, moving to a large city and starting a new, independent life, there are also problems that may seem insignificant at first glance but mean a lot for a foreigner. Among such problems, the following can be distinguished: the language barrier, unfamiliar climatic conditions, administrative difficulties, integration into another culture, new traditions, misunderstanding on the part of those around. Various problems connected with the adaptation of foreign students are discussed in works [1-13].

Some of the problems can be overcome with the help of preparatory courses for foreigners. Such courses help future students to adapt to new conditions in advance, prepare them to study at the university on a regular basis. However, many problems remain unsolved, therefore, it is especially important to find an individual approach to those students and try to help them to overcome arising difficulties.

The process of acquiring a profession of an engineer, designer, architect is quite complicated, and it requires a lot of effort and diligence. A solid foundation for studying

\footnotetext{
* Corresponding author: sna.spbgasu@gmail.com
} 
special courses is laid during the first year of studies by the course titled "Engineering Graphics".

Engineering Graphics is one of the fundamental courses necessary for students of civil engineering universities. During the first year of studies, this course should help students to develop such skills as the ability to interpret engineering and construction drawings, perform calculating and graphic operations, construct projection drawings of geometric objects, as well as develop knowledge of the rules of interpreting design and technical documents, rules of constructing drawings, freehand multi-view and axonometric drawings and diagrams. Thus, knowing the basic rules of working with drawings, understanding the principles of their creation, a student can acquire the necessary competencies in graphics [14]. It is worth mentioning the importance of successful mastering of this course by students who need to work with drawings in their subsequent professional activities.

The purpose of this study is to identify the most important problems associated with teaching such courses to foreign students and develop methods of their solution.

\section{Issues of adaptation to the educational process}

When studying the process of students' adaptation, it is necessary to take into account the opinion of students: during a conversation, many of them willingly share their problems and opinions about those things that might help them in studies. As a result of interviewing some foreign students, a number of conclusions on the issue under consideration were made:

What classes are the most difficult: practical classes or lectures?

Lectures proved to be the most difficult to grasp. The material is delivered continuously, includes a large number of special terms and drawings; unlike practical classes, lectures provide no possibility of a constant dialogue with a teacher.

\section{Is the Engineering Graphics course useful for foreign students?}

Insofar as students, having their major in the field of civil engineering, probably have to work with drawings in the future, the majority of them agree that such course in necessary. It should be noted that at the beginning first-year students have different competence levels: many students did not have such courses at school, therefore, they need additional classes to gain basic knowledge in this field. They lack particular skills in working with drawing tools.

Are foreign students satisfied with the current form of monitoring of academic performance?

Some foreign students are unaccustomed to the Russian system of knowledge evaluation. It can be difficult to understand new requirements and get used to them, as well as to the need to attend all classes and deliver all graphic works on time. It can be difficult to quickly and correctly formulate an answer during a test or examination. A significant advantage is that evaluation of knowledge in this field is performed in writing: there is an opportunity to think things over and correctly express thoughts, perform graphic constructions.

\section{Why do many foreign students often miss classes?}

Experience shows that foreign students miss classes more often than other students. This can be explained by various problems which foreigners face every day. Missing the first class may be a result of a schedule misunderstanding or a failure to find a lecture room; there are also such issues as the need to solve problems, associated with moving to Russia, during class time, complicated acclimatization in Saint Petersburg, etc. Those factors lead to the fact that already at the beginning of a term students are left with huge gaps in the basic knowledge in the field, and, subsequently, face problems with understanding everything that is based on those foundations.

Does it make sense to train foreign students according to a simplified program?

It is natural that most students are glad to have such opportunity and want to make their education easier. However, unfortunately, the same requirements stipulated by state 
educational standards apply to all students. The following option for solving the problem can be considered: it is possible to bring foreign students together in small individual groups where classes will be held with consideration for their particular needs. Thus, the educational process can become much more diverse and efficient.

\section{What can help foreign students to master the material studied in the most efficient way?}

Many students note that they lack specialized literature in their native language. If such literature is available in the library, then, as a rule, the structure of the course in it is somewhat different from the structure of the course taught in the university. Students also do not have enough time to complete assignments and prepare for classes: the general program of the course is mainly aimed at Russian students and does not take into account the difficulties that may arise with understanding texts of lectures and assignments, translating specialized literature, etc. Quite often, students having difficulties with studying do not dare to approach a teacher and ask for help, and, therefore, fail to deliver assignments on time, which entails poor academic performance. A way out of this situation proposed by many students is appointment of additional consultations, where they could ask their questions and discuss methods for completing assignments with a teacher.

What do foreign students aspire to when they come to Russia to study?

Foreign students come to study in Russian architecture and civil engineering universities to get a good education and become highly qualified experts in design. Many of them aspire to become builders, ecologists, architects. Foreign students are very diligent - they invest much more labor and effort in their studies than Russian students. Despite the fact that all students are educated under equal conditions, foreigners need much more time to learn and understand the material.

The list of questions touching upon this issue is not exhaustive. But it is obvious that teaching foreign students requires consideration of difficulties faced by such students when they come to live and study in an unfamiliar environment.

Further on, we will try to analyze the data obtained and present a number of methodological recommendations on teaching graphics to foreign students.

\section{Developed recommendations}

The work with foreign students requires a teacher to pay more attention to them, explain the material in more detail and in a way they can understand, and, as a consequence, spend much more time on that. The current method of teaching used in the education of most students requires a significant modification which will take into account problems of adaptation of foreign students.

A series of methodological recommendations has been developed, which can reduce the impact of negative factors and make the educational process more efficient. Those recommendations can be summarized as follows:

- Organization of an introductory (beginner's) course.

- Evaluation of the level of basic knowledge before the start of studies.

- Brief summary of fundamentals in the subject.

- Conducting additional consultations for foreign students.

- Precise wording of the requirements to the preparation of assignments.

- Working with teaching aids, video and audio materials.

- Monitoring of academic performance in writing.

- Bringing foreign students together in special groups.

- Involvement of foreign students in scientific activities. 
- Availability of specialized educational literature, corresponding to the course of lectures, in students' native language, is preferable.

Some of the proposed recommendations were tested in the educational process of the SPbSUACE in groups including foreign students. In particular, the following work was performed:

Additional consultations in Engineering Graphics were scheduled, during which students had the opportunity to ask questions and clarify wordings in educational materials.

Some wordings of assignments were revised, several complicated sentences were simplified.

Besides, as a result of the work performed, a draft study guide for the course was developed, which took into account many of the recommendations described above. Unlike the existing guides, this one is aimed not only at the general community of students, but at foreigners as well, because the material is not only presented in understandable wordings, but also supplemented with various graphic explanations, drawings and diagrams.

Special attention was paid to the visual presentation of the material in the developed guide, as illustrated materials, as a rule, convey the meaning more clearly and efficiently. This statement applies not only to foreign students, but to all students in general: if visual teaching methods are used as the basis for teaching graphics, then all spatial images and concepts will become more specific and understandable. A teacher who has mastered this method will be able to clearly explain to a student the essence of an assignment, as well as the requirements and the desired result.

A workbook could have an essential role in teaching foreign students. The sequence of tasks proposed by the workbook shall repeat the sequence of the materials set out in the study guide. This will make it possible to consolidate the material, covered during classroom studies, in due time.

The workbook shall include examples of all assignments and corresponding exercises; constructions can be presented in the form of step-by-step drawings helping to understand the assignment without any text. The workbook shall look like an A4 album.

Taking into account significant cross-cultural differences, mastering Russian alphabet combined with the engineering lettering requirements becomes quite a difficult and important task for many foreigners, requiring special attention. In this regard, the first pages of the workbook include assignments that are especially important for foreign students at the first stage of studies: working with lettering and lines of drawings.

There are methods that not only help students to understand the material, but also teach them how to express their thoughts in the most efficient way. Freehand axonometric drawing technique represents one of those methods. It is a freehand schematic image reflecting all key aspects of the original object. It can be a sectional view of a component, a sectional view of a quarter of a component, step-by-step construction; modification of an already drawn component: changing the shape, volume, removing unnecessary fragments, creating holes or protrusions. This approach makes it possible to highlight those characteristics of a complex objects that shall be paid special attention. It is crucial that a student is present during this process: if we demonstrate him/her the final image already prepared, then the desired effect will not be achieved. It is the process of step-by-step creation or modification of an object that allows a student to understand the essence and sequence of transformations.

Possessing the axonometric drawing technique can be useful not only for teachers, but also for students. Both in the process of studying at the university, and in future professional activities, it is very important not only to find the right solution, but also to be able to quickly and clearly formulate it. Expressing thoughts through a freehand axonometric drawing, a foreign student can easily overcome the language barrier.

In this regard, it is proposed to supplement the course of Engineering Graphics with an additional topic on the axonometric drawing technique, including, in particular, practical 
assignments. Those assignments are particularly important for students studying architecture and civil engineering. Thanks to those assignments, students will learn to apply this skill during the educational process and in their subsequent professional activities.

To help foreign students master Engineering Graphics, teachers are recommended to bring a focus on the visual presentation of the material during the educational process; apply modern methodological developments that take into account particular needs of foreign students; if possible, organize additional classes in the form of an introductory (beginner's) course; conduct supplementary consultations in addition to the current educational process.

Nowadays, there is a large number of multimedia and information technologies which make it possible to significantly improve the visual presentation and comprehensibility of the material delivered. In addition to the opportunity to consult electronic reference resources, available in the local network of a university, at any time, it is possible to interact with a teacher through a remote education system. During classes, a teacher can demonstrate already prepared presentations (including those prepared in several languages) and video materials to students using a projector. Besides, a document camera can provide significant advantages when teaching Engineering Graphics. All those means allow increasing the efficiency of the educational process and facilitate it not only for students, but also for teachers.

\section{Conclusion}

The majority of foreign students enter Russian universities for the sole purpose of getting a good education and becoming highly qualified experts. Foreign students spend much more time for learning and understanding the material than Russian students. The use of the abovementioned methodological recommendations can help to reduce the impact of negative factors of foreign students' adaptation and make the educational process more efficient.

\section{References}

1. Y. Zhou and J. Todman, Journal of Studies in International Education 13, 467 (2009). DOI: $10.1177 / 1028315308317937$

2. B. $\mathrm{Yu}$ and K. Downing, Educational Studies 38, 457 (2012). DOI: 10.1080/03055698.2011.643111

3. S.-Y. Chiang, Journal of International Migration and Integration 16, 397 (2015). DOI: 10.1007/s12134-014-0346-4

4. A.I. Clinciu, Procedia - Social and Behavioral Sciences 78, 718 (2013). DOI: 10.1016/j.sbspro.2013.04.382

5. J. Lee and A. Ciftci, International Journal of Intercultural Relations 38, 97 (2014). DOI: 10.1016/j.ijintrel.2013.08.009

6. C. Leung, International Journal of Psychology 36, 251 (2001). DOI: $10.1080 / 00207590143000018$

7. Y. Zhou, D. Jindal-Snape, K. Topping, and J. Todman, Studies in Higher Education 33, 63 (2008). DOI: 10.1080/03075070701794833

8. O. Lopez-Fernandez and J.L. Rodriguez-Illera, Computers \& Education 52, 608 (2009). DOI: 10.1016/j.compedu.2008.11.003

9. L. Sapranaviciute, A. Perminas, and N. Pauziene, Open Medicine 7 (2012). DOI: 10.2478/s11536-011-0161-7

10. M. Khodadoost, Z.D. Bashbarat, and R. Valizade, Procedia - Social and Behavioral Sciences 15, 2172 (2011). DOI: 10.1016/j.sbspro.2011.04.074 
11. C. Brisset, S. Safdar, J.R. Lewis, and C. Sabatier, International Journal of Intercultural Relations 34, 413 (2010). DOI: 10.1016/j.ijintrel.2010.02.009

12. V.I. Chirkov, S. Safdar, J. de Guzman, and K. Playford, International Journal of Intercultural Relations 32, 427 (2008). DOI: 10.1016/j.ijintrel.2007.12.001

13. Z. Cemalcilar, T. Falbo, and L.M. Stapleton, International Journal of Intercultural Relations 29, 91 (2005). DOI: 10.1016/j.ijintrel.2005.04.002

14. I.Yu. Amirdzhanova and V.G. Vitkalov, Vektor nauki TGU 26 (2015). 